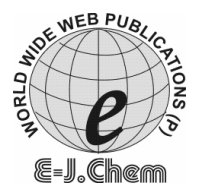

http://www.e-journals.net
ISSN: 0973-4945; CODEN ECJHAO

E-Journal of Chemistry

Vol. 5, No.3, pp. 593-597, July 2008

\title{
Simple Extractive Colorimetric Determination of Oxaprozin by Acid-Dye Complexation Methods in Solid Dosage Form
}

\author{
M. GANESH ${ }^{\S *}$, B. THANGABALAN ${ }^{\#}$, RAHUL PATIL $^{\S}$, \\ SWASTIKA GANGULY ${ }^{\S}$ and T. SIVAKUMAR ${ }^{\S}$ \\ ${ }^{\S}$ Department of Pharmaceutical Analysis, Nandha College of Pharmacy, Erode-638 052. \\ \#Department of Pharmacy, Donbosco PG College, \\ Verticherukurumandal, Guntur-522017(A.P). \\ ${ }^{\$}$ Department of Pharmaceutical Sci, BIT-Mesra, Ranchi, India \\ chemgans@gmail.com
}

Received 29 November 2007; Accepted 20 January 2008

\begin{abstract}
A simple and sensitive extractive spectrophometric method has been described for the assay of oxaprozin (OXA) either in pure form or in pharmaceutical solid dosage form. The developed method involves formation of colored chloroform extractable ion-pair complex of OXA with bromocresol green in aqueous acidic medium. The extracted complexes showed absorbance maxima at $421 \mathrm{~nm}$. Beer's law is obeyed in the concentration range of $10-50 \mu \mathrm{g} \mathrm{mL}^{-1}$. This method has been applied to the determination of drug in commercial tablets. Results of analysis were validated statistically. The excipients present in the formulations do not interfere with the assay procedure.
\end{abstract}

Keywords: Spectrophotometry, Oxaprozin, Bromocresol green, Ion-association complex.

\section{Introduction}

Oxaprozin (Figure 1), chemically known as 4,5-diphenyl-2-oxazole propionic acid ${ }^{1}$, is best known as a non-steroidal anti-inflammatory agent which is used for the treatment of pain, inflammation and rheumatic conditions ${ }^{2,3}$. Several chromatographic methods have been described in literature for the determination of OXA. It was separated and identified both by thin layer chromatography ${ }^{4}$ and gas chromatography ${ }^{5}$. A number of liquid chromatographic (LC) methods were reported for the determination of $\mathrm{OXA}^{6-9}$ in biological fluids. There is a LC method for the quantitative determination of OXA and its impurities in the bulk drug ${ }^{10}$.

Extractive spectrophotometric procedures are popular for their sensitivity in the assay of drugs and, therefore, ion-pair extractive spectrophotometry has received considerable attention for the quantitative determination of many pharmaceutical compounds. The aim of this study is the direct determination of OXA by extractive spectrophotometric method and the application to the solid dosage form. 


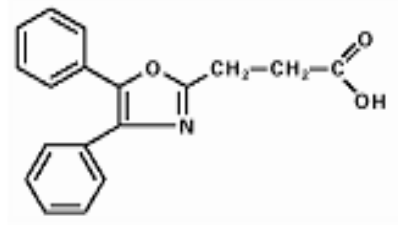

\section{Experimental}

Figure 1. Chemical structure of oxaprozin

\section{Apparatus}

A Elico UV-SL146 UV-V is spectrophotometer (Bombay) with $1 \mathrm{~cm}$ quartz cells was used for all absorbance measurements. Spectra were automatically obtained by Elico UV-SL146 system software. A calibrated digital $\mathrm{pH}$ meter was used for $\mathrm{pH}$ measurements.

\section{Reagents}

All chemicals were of analytical reagent grade of E.Merck unless otherwise specified. Doubly distilled water was used to prepare all solutions. Freshly prepared solutions were always employed. Potassium hydrogen phthalate buffer solution of $\mathrm{pH} 4$ was also prepared. $0.12 \%$ (w/v) Bromocresol green was prepared. Standard OXA was obtained from Dr. Reddy's Pharmaceuticals (Hyderabad, India) and tablets containing $600 \mathrm{mg}$ active material were kindly supplied from local stores.

\section{Standard solution of the drug}

A stock standard solution of $100 \mathrm{mg} \mathrm{mL}^{-1}$ was prepared by dissolving OXA in alcohol. Working standard solution was then prepared by suitable dilution of the stock standard solution with alcohol.

\section{Procedure for the assay of bulk sample}

From the $100 \mu \mathrm{g} \mathrm{mL}^{-1}$ solution, 1, 2, 3, 4 and $5 \mathrm{~mL}$ was transferred to a series of separating funnels and $2 \mathrm{~mL}$ of $\mathrm{pH}-4$ buffer was added to each and then $1 \mathrm{~mL}$ of $0.12 \% \mathrm{w} / \mathrm{v}$ bromocresol green was added and shaken well, and $10 \mathrm{~mL}$ of chloroform was added to each and shaken well and kept for few minutes. The chloroform layer was separated and treated with anhydrous sodium sulphate and the absorbance of the solution at $421 \mathrm{~nm}$ was measured against reagent blank. Final concentrations of analysed solutions were $10 \mu \mathrm{g} \mathrm{mL}^{-1}$ to $50 \mu \mathrm{g} \mathrm{mL} \mathrm{L}^{-1}$. The standard calibration plot was prepared to calculate the amount of the analyte drug in unknown samples.

\section{Procedure for formulations}

The total content of the tablet was weighed and grounded to a fine powder using a pestle and mortar. The average weight of a tablet was calculated. An accurately weighed portion of the powder equivalent to $50.0 \mathrm{mg}$ of OXA was transferred into a $50 \mathrm{~mL}$ volumetric flask. The volume was made up to the mark with the alcohol, shaken well and filtered through a Whatman filter paper No.40. Convenient aliquots from this solution were taken for the determination of OXA by BCG in the range 10 to $50 \mu \mathrm{gL}^{-1}$.

\section{Results and Discussion}

Anionic dye like BCG form ion-association complex with the positively charged drug. The drug-dye stoichiometric ratio as calculated by the continuous variation and mole-ratio method is found to be 1:1 with BCG. The drug-dye complex, with two oppositely charged ions, behaves as a single unit held together by an electrostatic force of attraction. 


\section{Spectral characteristics}

Absorption spectra of the yellow drug-BCG ion-pair complex with its $\lambda_{\max }$ at $421 \mathrm{~nm}$ shown in the Figure 2. The colorless blank is practically negligible absorbance.

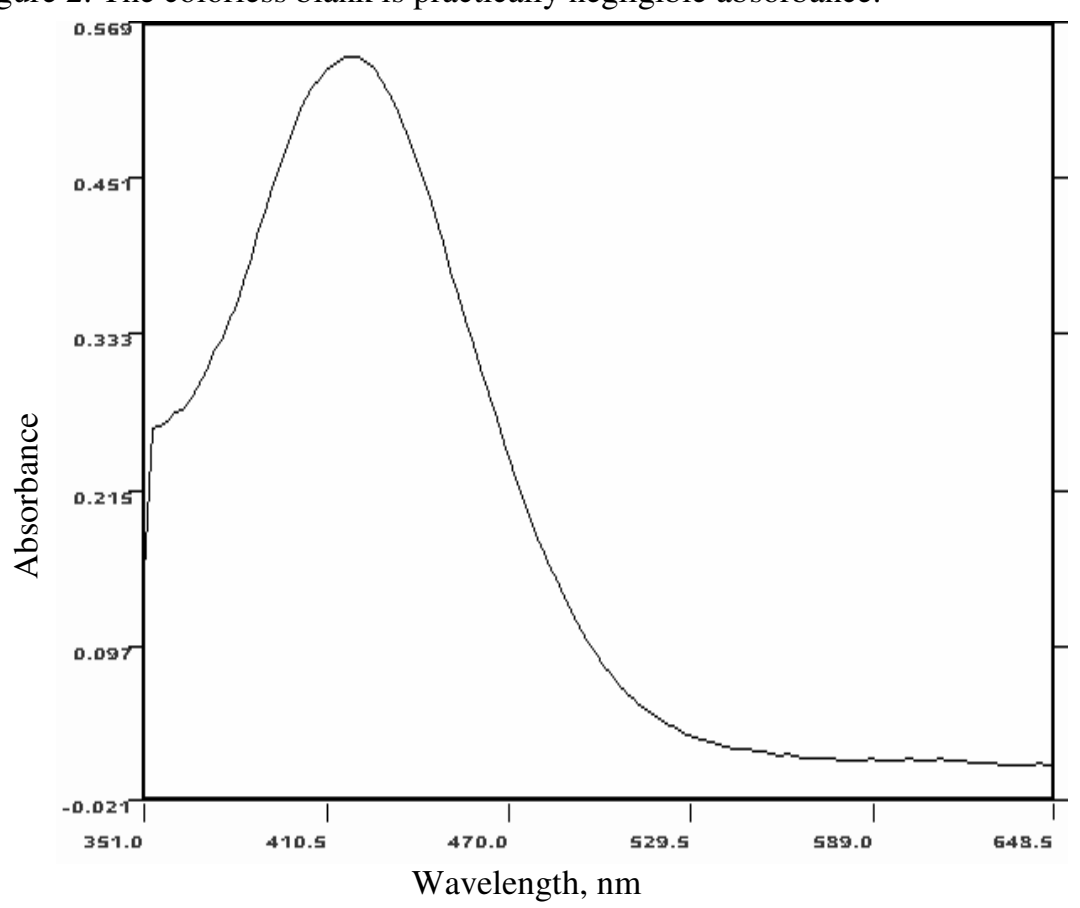

Figure 2. Absorption spectra of OXA-BCG complex extracted into $10 \mathrm{~mL}$ chloroform:

(OXA $=30 \mu \mathrm{g} \mathrm{mL}{ }^{-1}+1 \mathrm{~mL}$ of $0.12 \%$ (w/v) $\mathrm{BCG}+2 \mathrm{~mL}$ of $\mathrm{pH} 4$ buffer against blank.)

\section{Optimization of variables}

Optimum conditions necessary for rapid and quantitative formation of colored ion-pair complexes with maximum stability and sensitivity were established by a number of preliminary experiments. Potassium hydrogen phthalate buffer was found to be suitable for this method. Chloroform was preferred to other solvents (carbon tetrachloride, dichloromethane and ether) for this method for its selective and quantitative extraction. Optimum conditions were fixed by varying one parameter at a time while keeping other parameters constant and observing its effect on the absorbance at $421 \mathrm{~nm}$ for BCG. The effect of $\mathrm{pH}$ was studied (Figure 3 ) by extracting the colored complex species at different $\mathrm{pH}$. A maximal absorbance was observed at the $\mathrm{pH} 4.0$ and using $2 \mathrm{~mL}$ of buffer. A volume of $1 \mathrm{~mL}$ of $0.12 \%(\mathrm{w} / \mathrm{v}) \mathrm{BCG}$ was found to be optimal for complete complexation.

\section{Linearity and range}

Beer's law range, molar absorptivity, Sandell's sensitivity, regression equation, and correlation coefficient determined for this method are given in Table 1. A linear relationship was obtained in the concentration range of 10 to $50 \mu \mathrm{g} \mathrm{mL}^{-1}$. Regression analysis of the Beer's law plots reveals a good correlation. The graphs show negligible intercept and are described by the regression equation, $\mathrm{Y}=\mathrm{mX}+\mathrm{C}$ (where $\mathrm{Y}$ is the absorbance of $1 \mathrm{~cm}$ layer, $\mathrm{m}$ is the slope, $\mathrm{C}$ is the intercept and $\mathrm{X}$ is the concentration of the measured solution in $\mu \mathrm{g} \mathrm{mL} \mathrm{m}^{-1}$. The high molar absorptivities of the resulting complexes indicate the high sensitivity of this method. 


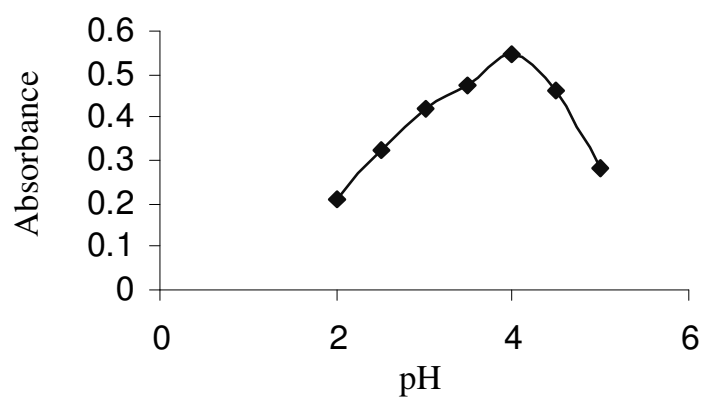

Figure 3. Effect of $\mathrm{pH}$ on the absorbance of OXA $\left(30 \mu \mathrm{g} \mathrm{mL} \mathrm{L}^{-1}\right)$ - BCG $(1 \mathrm{~mL}$ of $0.12 \%(\mathrm{w} / \mathrm{v})$.

Table 1. Optical characteristics, precision and accuracy of the propose method

\begin{tabular}{ll}
\hline Parameters & Values \\
\hline$\lambda_{\text {max }}, \mathrm{nm}$ & 421 \\
Beer's law limit, $\mu \mathrm{g} \mathrm{mL}^{-1}$ & $10-50$ \\
Molar absorptivity, $1 \mathrm{moL}^{-1} \mathrm{~cm}^{-1}$ & $5.3388 \times 10^{3}$ \\
Sandell's sensitivity & 0.0052 \\
$\left(\mu \mathrm{g} \mathrm{cm}{ }^{-2}\right.$ per 0.001 absorbance unit) & \\
Linear regression equation & \\
$Y=m X+C *$ Slope, $\mathrm{m}$ & $2.7 \times 10^{-3}$ \\
Standard Deviation of Slope & $0.12 \times 10^{-2}$ \\
Intercept (C) & $1.81 \times 10^{-2}$ \\
Standard Deviation of Intercept & $0.012 \times 10^{-3}$ \\
Correlation coefficient $\left(\mathrm{R}^{2}\right)$ & 0.9993 \\
$\%$ Range of error (Confidence limits) & \\
0.05 level & 0.131 \\
0.01 level & 0.060 \\
\hline
\end{tabular}

Where $\mathrm{Y}$ is absorbance and $\mathrm{X}$ is the concentration $\left(\mu \mathrm{g} \mathrm{mL} L^{-1}\right)$,

${ }^{a}$ Average of five determination

\section{Validation of the method}

Samples of pure OXA were prepared and tested at four levels of drug using the proposed procedure. The complete set of validation assay was performed for drug, determined by the proposed methods. The results obtained for formulation are given in Table 2 . The precision and accuracy of this method were tested by analyzing six replicates of the drug. The standard deviation, relative standard deviation, recovery and were determined from the calibration curve, as recorded in Table 2. The accuracy of the method is indicated by the excellent recovery $(99.96-100.21 \%)$ and the precision is supported by the low standard deviation $<0.09$.

Table 2. Assay results of OXA in tablets

\begin{tabular}{lccc}
\hline Drug & $\begin{array}{c}\text { Label Claim, } \\
\text { mg per tablet }\end{array}$ & $\begin{array}{c}\text { Amount found, } \\
\text { mg* }\end{array}$ & \% Recovery* \pm \% R.S.D \\
\hline Sample I & 600 & 599.98 & $100.38 \pm 0.572$ \\
Sample II & 600 & 600.16 & $100.19 \pm 0.317$ \\
\hline
\end{tabular}

\footnotetext{
* Average of five determinations.
} 


\section{Tablets analysis}

The proposed method was applied to the determination of OXA in commercial tablets. The applicability of the proposed method for the assay of OXA in tablet formulation was examined by analyzing various formulations and the results obtained were tabulated in Table 2. Satisfactory results were obtained for drug and were in a good agreement with the label claims (Table 2). The results were reproducible with low R.S.D. values. The average percent recoveries obtained were quantitative (9.96-100.21\%), indicating good accuracy of this method. The results of analysis of the commercial tablets and the recovery study of drug suggested that there is no interference from any excipients (such as starch, lactose, titanium dioxide, and magnesium stearate), which are present in tablets.

\section{Conclusion}

The proposed method can be used for determination of OXA in tablets. This method is simple rapid and has great sensitivity and accuracy. Proposed method makes use of simple reagent, which an ordinary analytical laboratory can afford. This method is suitable for routine determination of OXA in its formulations. The commonly used additives such as starch, lactose, titanium dioxide and magnesium stearate do not interfere with the assay procedures.

\section{References}

1. Merck Index, An Encyclopedia of Chemicals and Pharmaceuticals, Merk \&Co Inc Whitehouse station, 2005, $13^{\text {th }} \mathrm{Ed}$, pp 1095

2. Hubsher J A, Northington R S and Walker B R, Arthritis Rheum 1982, 26, 117.

3. Brown K, Cavalla J F, Green D and Wilson A B, Nature, 1968, 219, 164.

4. Pierce D M, Xenobiotica, 1981, 11, 857-862.

5. Janssen F W, Kirkman S K, Knowles J A and Ruelius H W, Drug Metab. Dispos, 1978, 465.

6. McHugh L S, Kirkman S K, Knowles J A and John A, J Pharm. Sci.1980, 69, 794-796.

7. Matlis R and Grenblat D J, J Chromatogr, 1984, 310, 445-449.

8. Kurowski M and Thabe H, Agents \& Actions, 1989, 27, 458-460.

9. Chiang S T, Knowles J A, Hubsher J A, Ruelius H W and Walker B R, J. Clin. Pharmacol, 984, 24, 381-385.

10. Krishna Reddy K V S R, Sreenivas Rao D, Vyas K and Om Reddy G, J Pharm Biomed. Anal, 2000, 22, 651- 659. 


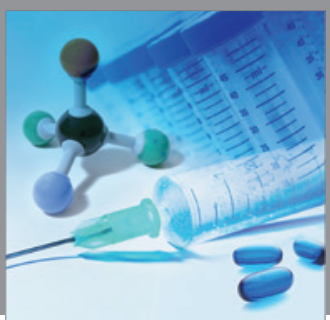

International Journal of

Medicinal Chemistry

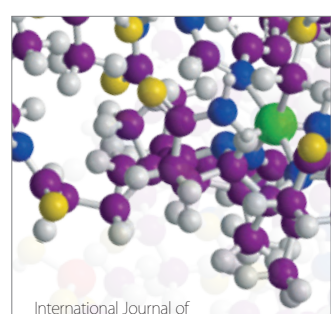

Carbohydrate Chemistry

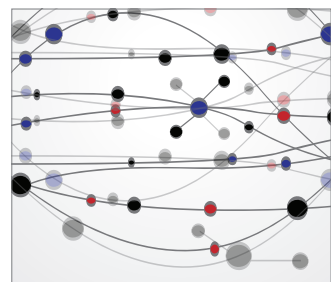

The Scientific World Journal
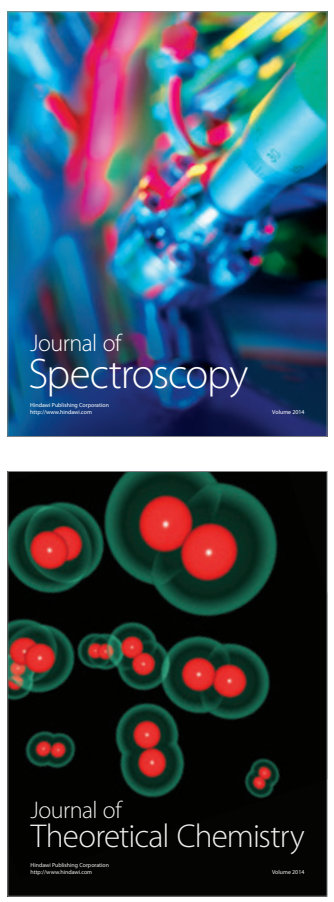
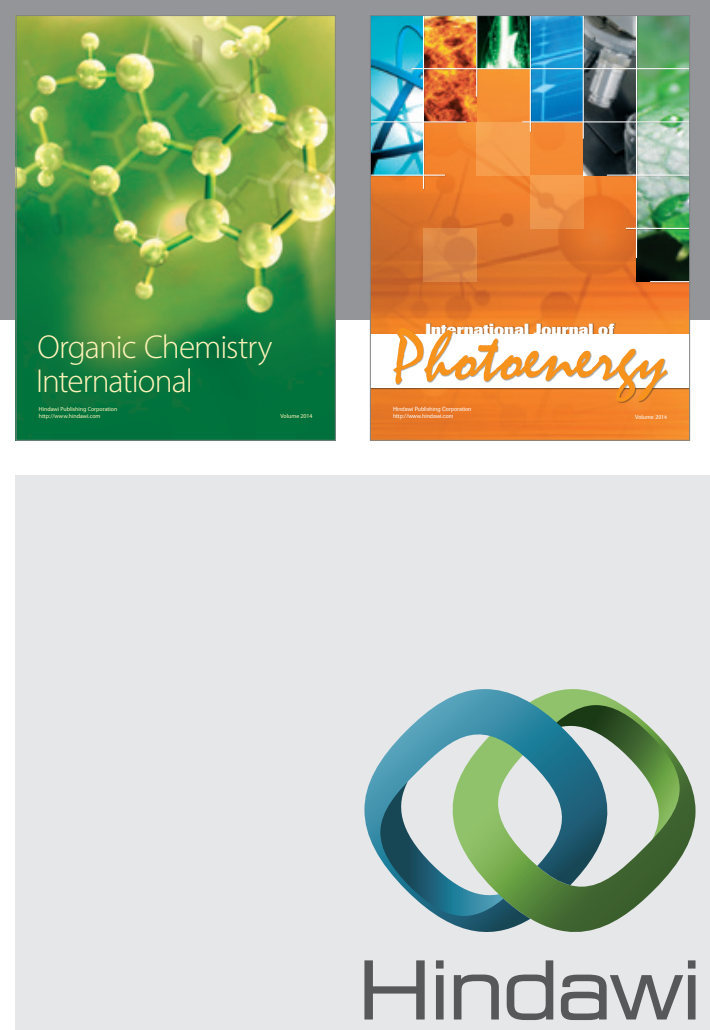

Submit your manuscripts at

http://www.hindawi.com
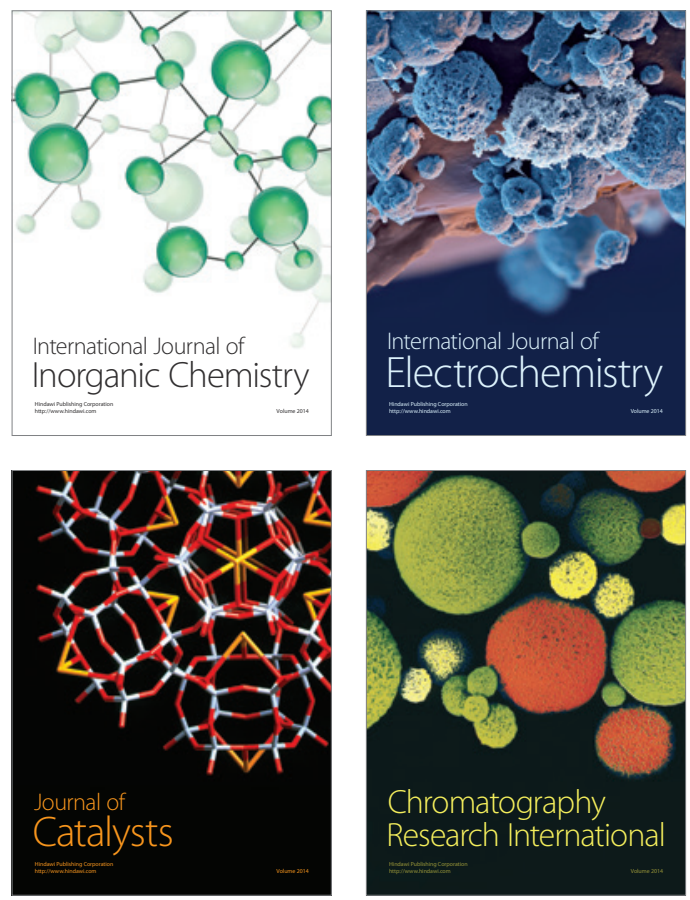
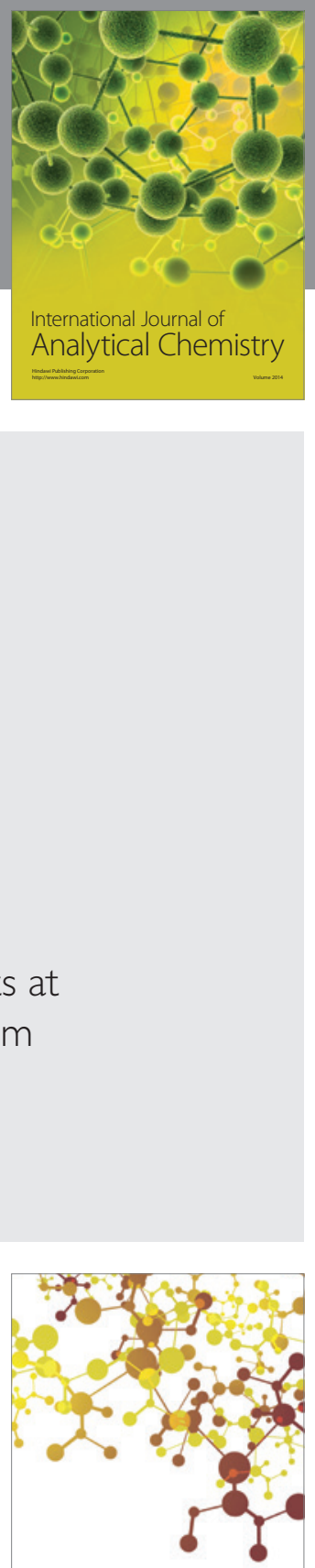

Journal of

Applied Chemistry
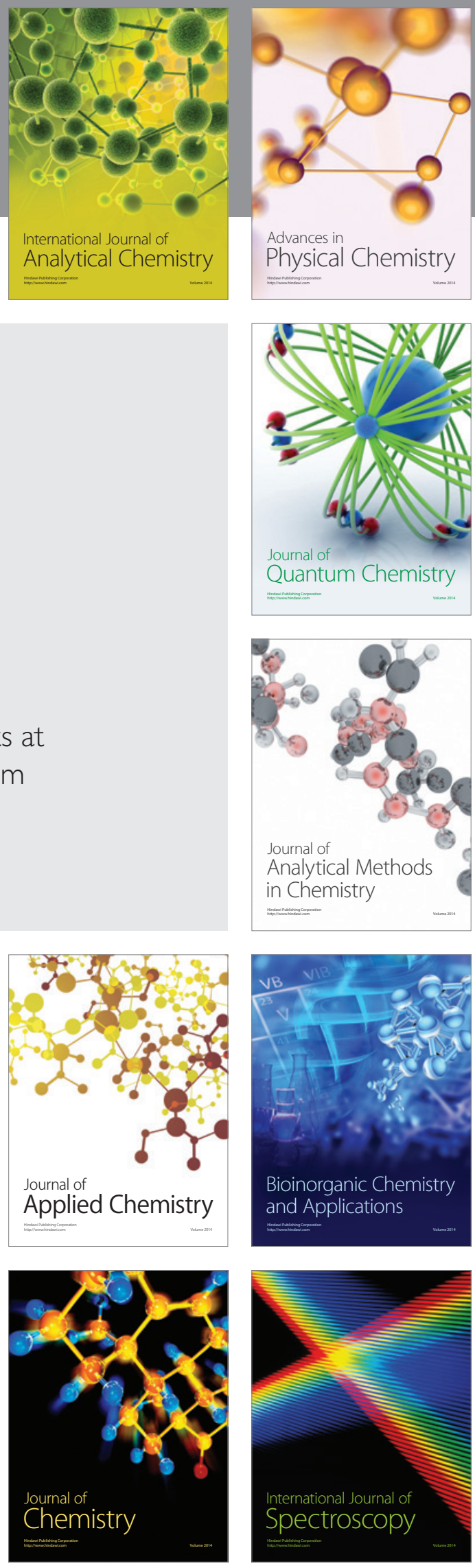